\title{
Keberlanjutan Usaha Songket Lombok Melalui Pemberdayaan Penenun dan Media Informasi Produk
}

\author{
Sri Sukarni*1, Baiq Herdina Septika² \\ ${ }^{1)}$ Fakultas Ilmu Seni, Universitas Nusa Tenggara Barat \\ ${ }^{2)}$ Fakultas Ekonomi, Universitas Nusa Tenggara Barat
}

\begin{abstract}
Kata Kunci: Abstrak: There are many efforts in maintaining continuity of Songket Sukarara empowerment business. One of the efforts is through empowerment artisans weaving Songket. artisans weaving The empowerment artisans weaving Songket can be done by giving them training. Songket, Indonesian and English Training, Marketing Management Training, Songket Brochure Communication training about ability to speak in Indonesian and English are useful for both artisans weaving Songket and company. The other trainings are marketing and production management. This community service is held at UD. Undur Pasang Sukarara Central Lombok Regency that produced and sold Lombok Songket. Many artisans weaving Songket have less ability to explain the product. Besides, UD. Undur Pasang does not have a book for expenditure and income for money and goods that are neatly arranged and neither songket brochure. Based on the problems, training about communication ability, marketing management and brochure as information media are needed. This community service activity aimed to: 1) provide Indonesian and English training to artisans weaving Songket and staffs; 2) make two kinds of brochures about Songket produced and sold by UD. Undur Pasang in Indonesian and English; 4) develop staffs and artisans weaving Songket ability on product and marketing management. There are three steps in this community service namely preparation, implementation and evaluation. The result of community service showed 1) artisans weaving Songket and staffs' performance is fairly enough both in Indonesian and English; 2) brochure about Undur Pasang product and Songket are provided; 3) UD. Undur Pasang applied new marketing and product management.
\end{abstract}

\section{Korespondensi: srisukarni_untb@yahoo.com}

\section{PENDAHULUAN}

Dalam menghadapi persaingan, Usaha Mikro Kecil dan Menengah (UMKM) dituntut untuk melalukan beberapa upaya dengan tujuan untuk memenuhi permintaan konsumen yang semakin spesifik, berubah dengan cepat dan produk yang berkualitas. Salah satu upaya yang dapat dilakukan UMKM adalah melalui pemberdayaan masyarakat. Pemberdayaan masyarakat melalui UMKM sering menjadi tema sentral yang diangkat ke permukaan dan juga menjadi perhatian pemerintah.

Empowerment atau pemberdayaan adalah pemberian wewenang, pendelegasian wewenang atau pemberian otonomi kejajaran bawah (Widjaya, 2002: 77). Sedangkan menurut Suharto (2009: 60) pemberdayaan sebagai suatu proses dan tujuan. Pemberdayaan sebagai suatu proses untuk memperkuat keberdayaan kelompok lemah dalam masyarakat sedangkan tujuan yang ingin dicapai adalah mewujudkan masyarakat yang berdaya, memiliki pengetahuan serta mandiri dan mampu bersaing. Selanjutnya Mardikanto dan Soebianto (2013:170) menetapkan adanya lima program strategi pemberdayaan yang terdiri dari pengembangan sumber 
daya manusia, pengembangan kelembagaan kelompok, pemupukan modal masyarakat (swasta), pengembangan usaha produktif, penyediaan informasi tepat guna.

Berdasarkan penjelasan diatas, maka dampak pemberdayaan adalah kesejahteraan masyarakat baik dari aspek pendidikan, kesehatan dan pendapatan yang sesuai dengan tujuan pembangunan. Oleh karena itu, untuk meningkatkan kualitas pembangunan manusia diperlukan pembangunan pada sektor ekonomi misalnya melalui kerajinan tenun.

Di wilayah Pulau Lombok dikembangkan usaha tenun songket yang dikerjakan oleh kaum Ibu. Beberapa daerah yang masih bertahan hingga saat ini, antara lain: 1) Lombok Timur terdapat di desa Pringgasela, Kembang Kerang, Dasan Nyiur dan Desa Sukaraja; 2) Lombok Tengah terdapat di desa Sukarara, Rembitan, Sade dan Ganti; 3) Lombok Utara terdapat di desa Sokong dan Desa Bayan. (Alimudin, 2010: 11).

Desa Sukarara merupakan salah satu kawasan sentra produksi dan penjualan Songket dan merupakan suatu daerah usaha pengembangan Songket Lombok. Kerajinan menenun songket sudah dimiliki oleh masyarakat setempat dari warisan pendahulunya yang dikembangkan secara turun-temurun. Keindahan produk tenun Songket Sukarara sudah dikenal oleh khalayak luas. Wisatawan asing maupun domestik sering mendatangi desa Sukarara untuk membeli dan memesan kain Songket Sukarara.

UD. Undur Pasang memproduksi dan menjual Songket Sukarara, berdiri pada bulan April 2007. Unit produksi tenun songket Lombok ini jarang dikunjungi oleh para wisatawan baik domestik maupun manca negara, padahal kerajinan Songket Lombok menjadi salah satu daya tarik pariwisata di pulau Lombok. Di sisi lain industri Songket menyerap tenaga kerja.

Survey yang telah dilakukan oleh tim Pengabdian Pada Masyarakat melalui Program Kemitraaan Masyarakat (PKM) Universitas Nusa Tenggara Barat (UNTB) ditemukan bahwa permasalahannya terletak pada Sumber Daya Manusia, media pemasaran/informasi dan manajemen usaha. Potensi sumber daya manusia berdampak terhadap perkembangan suatu perusahaan sebagaimana dikatakan oleh Gaol bahwa Sumber Daya Manusia merupakan potensi yang menjadi penggerak organisasi (2014:44). Sebagai penggerak organisasi maka pemberdayaan sumber daya manusia diperlukan dalam perusahaan. Keberhasilan suatu perusahaan tidak hanya tergantung pada Sumber Daya Alam dan teknologi saja tetapi juga tergantung pada pengelolaan Sumber Daya Manusia.

Sebagian besar penenun songket yang dimiliki oleh UD. Undur Pasang masih belum memiliki kemampuan untuk menjelaskan motif dan makna songket. Disamping itu juga UD. Undur Pasang belum memiliki brosur dan buku tentang songket produk UD. Undur Pasang. Cara penjualan/pemasaran yang dilakukan selama ini adalah dengan menjual langsung ke pelanggan di kantor-kator, rumah-rumah pelanggan.

Permasalahan mitra yang menjadi latar belakang dilaksanakannya Program Kemitraan Masyarakat adalah: 
1. Masih rendahnya kemampuan penenun produk UD. Undur Pasang dalam bahasa Indonesia dan bahasa Inggris;

2. Tidak tersedianya informasi berupa brosur tentang Songket Lombok dalam bahasa Indonesia maupun bahasa Inggris yang disediakan oleh UD. UNDUR PASANG yang merupakan sarana promosi;

3. Belum ada buku yang memuat penjelasan tentang Songket Lombok;

4. Masih kurangnya pengetahuan para penenun tentang manajemen pemasaran hasil usaha produksi Songket.

Berdasarkan analisis situasi dan permasalahan maka solusi pelaksanaan Program Kemitraan Masyarakat ini sebagai berikut:

1. Memberikankan pelatihan bahasa Indonesia dan Inggris bagi penenun Songket di UD. Undur Pasang. Pelatihan komunikasi diberikan karena komunikasi adalah keterampilan manajemen yang sering digunakan dan sering disebut sebagai satu kemampuan yang mendukung bagi keberhasilan wirausahawan (Rusdiana, 2013:314). Disamping itu juga sebagai sarana komunikasi global, bahasa Inggris harus dikuasai secara aktif baik lisan maupun tulisan (Handayani: 2016). Penguasaan terhadap bahasa Inggris berdampak pada pengembangan Sumber Daya Manusia dan perusahaan. Berkembangnya keterampilan penenun dalam bidang komunikasi akan berdampak pada perkembangan tenun Songket Lombok sebagai salah satu bentuk industri di sektor kerajinan.

2. Membuat brosur dalam bahasa Indonesia dan bahasa Inggris tentang koleksi Songket UD. Undur Pasang

3. Membuat buku tentang Songket

4. Meningkatkan pengetahuan para pengrajin dan manajemen UD. Undur Pasang tentang tentang manajemen usaha dan produksi.

\section{METODE KEGIATAN}

Metode Pelaksanaan Program Kemitraan Masyarakat ini terdiri dari

\section{Persiapan}

a. Observasi/survey kepada sasaran Program Kemitraan Masyarakat

b. Sosialisasi: bertujuan untuk memberikan informasi kepada Mitra dan penenun Songket Lombok sebagai bentuk penguatan komitmen untuk mensukseskan kegiatan Program Kemitraan Masyarakat. Tim Pelaksana akan memberikan informasi tentang pentingnya kemampuan bahasa Inggris dan bahasa Indonesia untuk menunjang dan mengembangkan UD. Undur Pasang yang dimiliki oleh Mitra.

c. Persiapan kegiatan: bertujuan untuk mengidentifikasikan dan menyiapkan kebutuhan pelaksanaan kegiatan. Persiapan kegiatan dilaksanakan bersama-sama dengan Mitra dan kegiatannya terdiri dari:

- Persiapan materi/bahan pelatihan

- Tempat, waktu pelatihan, peserta

- Mekanisme pelaksanaan 


\section{Pelaksanaan}

a. Pelatihan bahasa Indonesia dan bahasa Inggris : merupakan kegiatan awal dari pelaksanaan PKM. Materi dan praktek komunikasi bahasa Indonesia dan bahasa Inggris praktis berbasis Songket Lombok dan produk UD. Undur Pasang. Pelaksanaan pelatihan dibagi menjadi tiga tahap:

1. Tahap pertama: fokus pada penyampaian materi komunikasi praktis bahasa Inggris dan bahasa Indonesia

2. Tahap kedua: fokus pada penyampaian materi yang berhubungan dengan Songket Lombok dan produk UD. Undur Pasang

3. Tahap ketiga: fokus pada praktek langsung materi pada tahap pertama dan kedua

- Pelaksanaan pelatihan bahasa Indonesia dan bahasa Inggris dilaksanakan di UD. Undur Pasang pada hari Rabu, Sabtu dan Minggu. Pelatihan kedua materi tersebut dilaksanakan sekaligus dengan cara mengajarkan bahasa Indonesia terlebih dahulu dan setelah itu materi bahasa Inggris.

- Materi ajar pelatihan bahasa Indonesia terdiri dari memberi salam, memperkenalkan diri dan orang lain, mempersilahkan tamu, bilangan, warna, menerangkan nama benda/obyek, menerangkan nama produk UD. Undur Pasang, mendeskripsikan songket, bahan dan alat untuk menenun songket, mendeskripsikan proses membuat songket. Sedangkan materi ajar pelatihan bahasa Inggris adalah Greeting and introducing, Number, Color, Describing product of UD. Undur Pasang, Describing about Songket, Material and tool to make songket, Telling the process of weaving songket, Dialog between weaver and guests/buyers.

b. Pembuatan brosur kain tenun Songket Lombok yang diproduksi oleh UD. Undur Pasang. Brosur terdiri dari dua macam yaitu brosur dalam bahasa Indonesia dan bahasa Inggris. Kedua brosur tersebut berisi mendeskripsikan tentang songket koleksi UD. Undur Pasang.

c. Pembuatan buku tentang Songket koleksi UD. Undur Pasang, motif dan kegunaannya

d. Pelatihan Manajemen Pemasaran hasil produksi Songket dilaksanakan agar manajemen UD. Undur Pasang dapat memiliki kemampuan tentang manajemen usaha dan mencoba melakukan hal yang baru dalam pemasaran produksi misalnya dengan cara pemasaran secara online. Pimpinan dan staf diberi pelatihan tentang buku kas sederhana. Pemasaran hasil produksi songket koleksi UD. Undur Pasang secara online juga diajarkan dalam pelatihan tersebut.

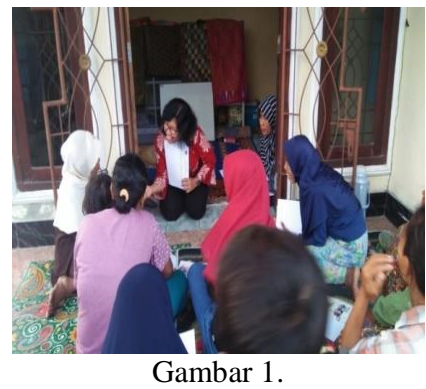

Kegiatan pelatihan komunikasi

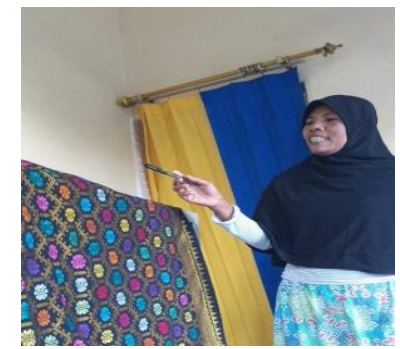

Gambar 2. Praktek dalam Bahasa Inggris

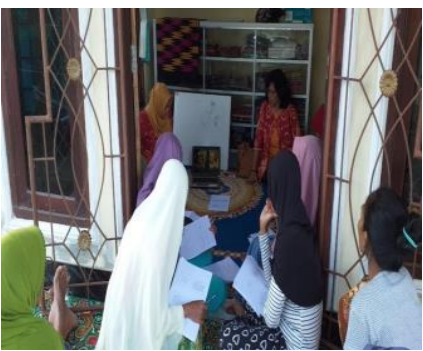

Gambar 3. Pelatihan Manajemen Pemasaran 


\section{HASIL DAN PEMBAHASAN}

UD. Undur Pasang pimpinan Lale Seriwati memiliki tenaga kerja sebagai penenun songket yang berjumlah 15 (lima belas) orang. Para penenun tersebut memiliki usia dan tingkat pendidikan yang beragam. Berikut adalah tabel data penenun songket di UD. Undur Pasang menurut usia dan tingkat pendidikan.

Tabel. 1. Klasifikasi usia Penenun Songket UD. Undur Pasang

\begin{tabular}{|c|c|c|c|c|}
\hline $25-35$ & $35-45$ & $45-55$ & $55-65$ & Jumlah \\
\hline 6 & 5 & 2 & 2 & 15 \\
\hline
\end{tabular}

Tabel 2. Klasifikasi Pendidikan Penenun Songket UD. Undur Pasang

\begin{tabular}{|c|c|c|c|c|}
\hline $\begin{array}{c}\text { Tidak/Belum } \\
\text { Tamat SD }\end{array}$ & SD & SMP & $\begin{array}{c}\text { SMA/Kejar } \\
\text { Paket C }\end{array}$ & Jumlah \\
\hline 3 & 2 & 8 & 2 & 15 \\
\hline
\end{tabular}

Berdasarkan angket yang diberikan oleh tim pelaksana PKM menunjukkan dari 15 responden sebanyak 5 responden (33\%) menyatakan kurang memiliki kemampuan berkomunikasi dalam bahasa Indonesia dan bahasa Inggris. Sebanyak 7 responden (47\%) menyatakan tidak bisa berkomunikasi dalam bahasa Indonesia dan bahasa Inggris dan sebanyak 3 responden (20\%) menyatakan sangat tidak bisa berkomunikasi dalam bahasa indonesia dan bahasa Inggris. Sebanyak 2 responden (13\%) menyatakan memiliki kemampuan yang baik dalam manajemen usaha. Sebanyak 4 responden (27\%) menyatakan kurang memiliki kemampuan dalam manajemen usaha. Sebanyak 5 responden (33\%) menyatakan tidak memiliki kemampuan dalam manajemen usaha dan sebanyak 4 responden $(27 \%)$ menyatakan sangat tidak memiliki kemampuan dalam manajemen usaha.

Hasil survey tersebut dijadikan dasar penyusunan materi pelatihan bahasa Indonesia, bahasa Inggris dan manajemen pemasaran/usaha. Pelatihan diselenggarakan di UD. Undur Pasang dari bulan Juli sampai dengan Agustus 2019 pada sore hari. Kemampuan bahasa Indonesia sebelum pelatihan menunjukkan rerata sebesar 5,4 dan setelah pelatihan sebesar 6,6. Untuk kemampuan bahasa Inggris sebelum pelatihan sebesar 5,3 dan sesudah pelatihan sebesar 6,4. Dari hasil tersebut terlihat ada peningkatan setelah pelatihan diberikan.

Disamping memberikan pelatihan bahasa Indonesia dan bahasa Inggris, tim pelaksana Program Kemitraan Masyarakat membuat bosur dan buku tentang songket yang diproduksi oleh UD. Undur Pasang. Buku dan brosur tersebut sebagai media pemasaran songket dan sebagai alat bantu para penenun dalam menjelaskan produk kepada para wisatawan/pembeli yang datang ke UD. Undur Pasang.
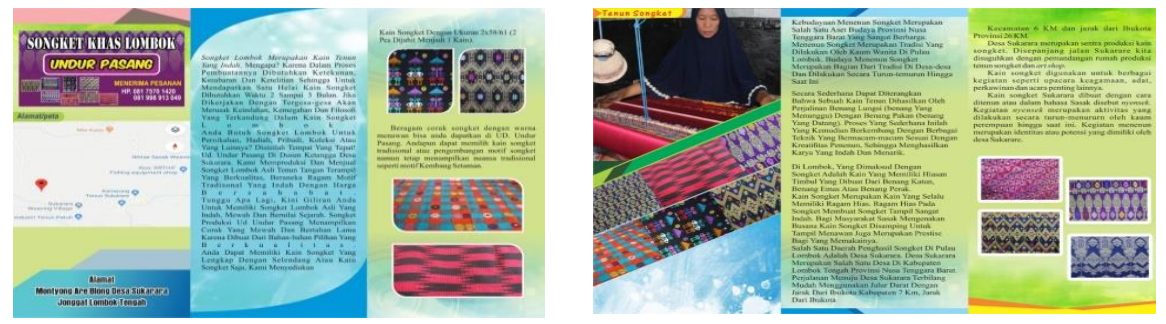

Gambar 4. Brosur dalam Bahasa Indonesia 

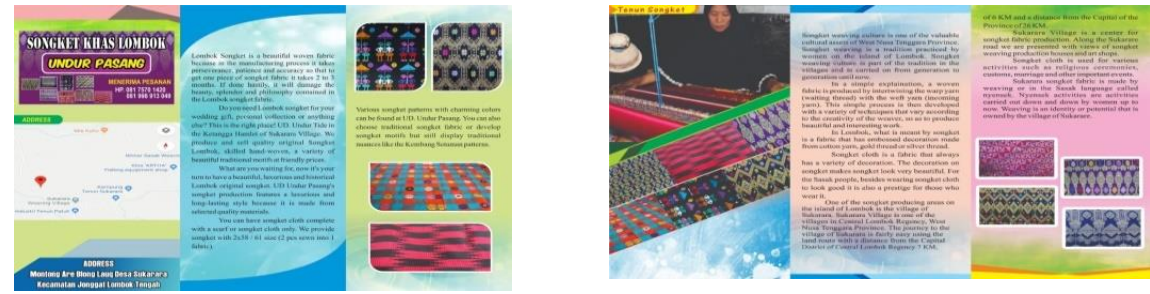

Gambar 5. Brosur dalam Bahasa Indonesia

\section{KESIMPULAN DAN SARAN}

\section{Kesimpulan}

Berdasarkan hasil pelaksanaan Program Kemitraan Masyarakat, maka dapat disimpulkan sebagai berikut:

a. Pemberdayaan penenun songket di UD. Undur pasang dilaksanakan melalui pelatihan komunikasi dan manajemen usaha

b. Pelatihan bahasa Inggris dan bahasa Indonesia bertujuan agar para penenun songket dapat menjelaskan dengan baik deskripsi songket dan produk UD. Undur Pasang. Kemampuan bahasa Indonesia dan bahasa Inggris para penenun setelah pelatihan dapat dikategorikan cukup dengan rerata 6,6 dan 6,4

c. Pelatihan manajemen usaha bertujuan agar para penenun dan manajemen UD. Undur Pasang dapat meningkatkan produktivitas usahanya

d. Brosur dan buku songket dapat dijadikan media promosi songket produk UD. Undur Pasang.

\section{Saran}

Berdasarkan kesimpulan, maka disarankan pemerintah dan masyarakat dapat membantu mempromosikan tenun songket Lombok tidak hanya di daerah Lombok saja tetapi sampai keluar daerah bahkan ke mancanegara. Selain itu juga diharapkan pemerintah memperhatikan kelangsungan usaha industri kecil tenun songket Lombok dengan melakukan pelatihan pembinaan dan pendampingan secara berkesinambungan kepada penenun songket yang ada di Desa Sukarara.

\section{Ucapan Terima Kasih}

Tim pelaksana Program Kemitraan Masyarakat mengucapkan terima kasih kepada:

1. Ristekditi yang telah memberi dukungan financial untuk terlaksananya Program Kemitraan Masyarakat ini

2. LLDIKTI Wilayah VIII yang telah membantu pelaksanaan PKM dengan memberikan informasi tentang program Pengabdian Pada Masyarakat

3. Pimpinan dan Penenun Songket UD. Undur Pasang sebagai Mitra atas partisipasinya sehingga PKM dapat dilaksanakan 


\section{DAFTAR PUSTAKA}

Gaol, CHR. Jimmy L, 2014. A to Z Human Capital (Manajemen Sumber Daya Manusia) Konsep, Teori, dan Pengembangan Dalam Konteks Organisasi Publik dan Bisnis, PT. Gramedia Widiasarana: Jakarta

Handayani, Sri. (2016). Pentingnya Kemampuan Bahasa Inggris Dalam Menyongsong Asean Community 2015. Ikatan Sarjana Pendidikan Indonesia (ISPI) Jawa Tengah, Volume 3 Nomor 1, Mei 2016.

Mardikanto, Totok dan Poerwoko Soebianto. 2013. Pemberdayaan Masyarakat: Dalam Perspektif Kebijakan Publik. Alfabeta: Bandung

Mesir, Alimudin. 2010. Tenun Tradisional Gedongan Lombok. Pustaka Widya: Mataram Rusdiana, 2013. Kewirausahaan Teori dan Praktek. Pustaka Setia: Bandung

Suharto, Edi. 2009. Membangun Masyarakat Memberdayakan Rakyat: Kajian Strategis Pembangunan Kesejahteraan Sosial dan Pekerjaan Sosial. Rafika Aditama:Bandung

Widjaya,HAW. 2002. Otonomi Daerah dan Daerah Otonom. Raja Grafindo Persada:Jakarta 